\title{
Outcomes of neonatal Ebstein's anomaly without right ventricular forward flow
}

\author{
Jae Suk Baek, MD, ${ }^{a}$ Jeong Jin Yu, MD, ${ }^{\mathrm{a}}$ Yu Mi Im, $\mathrm{PhD},{ }^{\mathrm{c}}$ and Tae-Jin Yun, $\mathrm{MD}, \mathrm{PhD}^{\mathrm{b}}$
}

\section{ABSTRACT}

Objective: In neonates with Ebstein's anomaly and absent right ventricular forward flow, pulmonary valve morphology is normal or abnormal. Although initial postnatal presentations of these 2 conditions are similar, clinical courses and therapeutic strategies for each category differ greatly.

Methods: Among 29 neonates with Ebstein's anomaly without right ventricular forward flow on initial postnatal echocardiography, 16 had a normal pulmonary valve and 13 had an abnormal pulmonary valve.

Results: During the postnatal follow-up of the normal pulmonary valve group, right ventricular forward flow commenced approximately 10 days after birth (1-15 days). The ductus arteriosus was surgically ligated in 3 neonates to facilitate right ventricular forward flow. Biventricular or $11 / 2$ ventricular physiology was eventually achieved in 14 patients in the normal pulmonary valve group (14/16, $88 \%)$ and 2 patients in the abnormal pulmonary valve group (2/13, 15.3\%). With respect to the preoperative echocardiographic findings, the normal pulmonary valve group had a significantly larger pulmonary valve annulus $(8.2 \pm 1.4 \mathrm{~mm}$ in the normal pulmonary valve group and $6.4 \pm 1.8 \mathrm{~mm}$ in the abnormal pulmonary valve group, $P=.002$ ) and smaller cardiothoracic ratio $(0.79 \pm 0.05$ in the normal pulmonary valve group and $0.85 \pm 0.07$ in the abnormal pulmonary valve group, $P=.03$ ). Mild to moderate pulmonary regurgitation was present in all patients $(16 / 16,100 \%)$ in the normal pulmonary valve group, but 3 patients $(3 / 13,23 \%)$ in the abnormal pulmonary valve group also had pulmonary regurgitation. On logistic regression analysis, only pulmonary valve annulus size remained as an indicator of a normal pulmonary valve $(P=.03)$.

Conclusions: In patients with Ebstein's anomaly and absent right ventricular forward flow, large pulmonary valve annulus size indicated a normal pulmonary valve. Patients with a normal pulmonary valve showed better survival and had a higher probability of achieving biventricular hemodynamics. (J Thorac Cardiovasc Surg 2016;152:516-21)

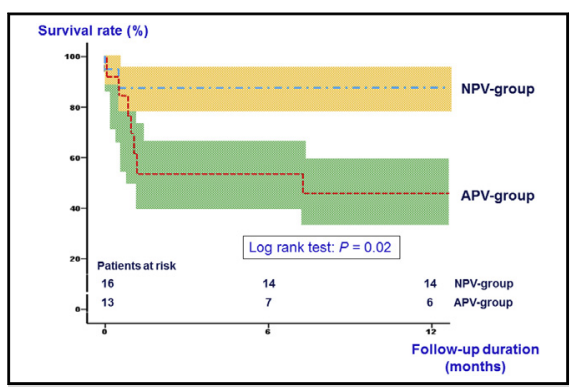

Clinical outcomes of the neonates with Ebstein's anomaly according to the PV morphology.

\section{Central Message}

Postnatal outcomes of Ebstein's anomaly without RVFF are determined by PV morphology.

\section{Perspective}

In neonates with Ebstein's anomaly and absent RVFF, the PV morphology may be normal or abnormal. The precise differentiation of these 2 conditions at initial presentation is critical. The former has a good prognosis and tends to achieve biventricular or $11 / 2$ ventricular physiology, whereas the latter has a bad prognosis and may lead to 1 -ventricle repair.

See Editorial Commentary page 522.
Newborn babies with severe Ebstein's anomaly may present with absent right ventricular forward flow (RVFF) even if the morphology of the pulmonary valve (PV) is normal. Given that RVFF usually commences within several days with the improvement in right ventricular (RV) contraction, the temporary absence of RVFF may be due to the mismatch

From the Divisions of ${ }^{\mathrm{a} P e d i a t r i c}$ Cardiology, and ${ }^{\mathrm{b}}$ Pediatric Cardiac Surgery, Asan Medical Center; and 'Seoul Women's College of Nursing, Seoul, South Korea.

Received for publication Sept 22, 2015; revisions received Feb 27, 2016; accepted for publication March 19, 2016; available ahead of print May 6, 2016.

Address for reprints: Tae-Jin Yun, MD, PhD, Division of Pediatric Cardiac Surgery,

Asan Medical Center, 388-1 Poongnap-dong, Songpa-gu, Seoul, Republic of

Korea, 138-736 (E-mail: tjyun@amc.seoul.kr).

$0022-5223 / \$ 36.00$

Copyright (c) 2016 by The American Association for Thoracic Surgery

http://dx.doi.org/10.1016/j.jtcvs.2016.03.084 between RV contractility and afterload. Use of prostaglandin E-1 to maintain ductal patency may hinder or at least delay the development of RVFF. Once RVFF develops, however, cardiomegaly and tricuspid regurgitation (TR) gradually diminish (Figure 1). Limiting the ductal patency in a timely fashion, either by discontinuation of prostaglandin infusion or by surgical closure, may be necessary to prevent a devastating circular shunt in this setting.

Scanning this QR code will take you to the article title page.

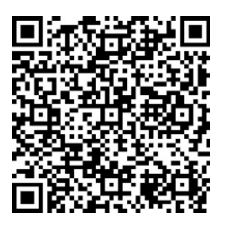



Abbreviations and Acronyms
$\mathrm{APV}=$ abnormal pulmonary valve
GOSH $=$ Great Ormond Street Hospital
$\mathrm{LV}=$ left ventricular, left ventricle
$\mathrm{NPV}=$ normal pulmonary valve
$\mathrm{PR}=$ pulmonary regurgitation
$\mathrm{PV}=$ pulmonary valve
PVA $=$ pulmonary valve annulus
$\mathrm{RV}=$ right ventricular, right ventricle
$\mathrm{RVFF}=$ right ventricular forward flow
TR = tricuspid regurgitation

Meanwhile, there is another subset of patients with $\mathrm{Eb}$ stein's anomaly who have a dysmorphic and nonfunctioning PV. RVFF does not develop spontaneously in this cohort, and maintenance of ductal patency is critical for survival. $\mathrm{RV}$ decompression may be attempted if the RV contractility is fairly preserved, but early RV exclusion for single ventricle management is more frequently indicated..$^{2-6}$ Because these 2 conditions have different prognoses and require different therapeutic strategies, it is important to discriminate one from the other as soon as possible after birth. For instance, a mistakenly diagnosed abnormal pulmonary valve (APV) in patients with a normal pulmonary valve (NPV) may lead to an inappropriate RV exclusion, whereas a mistakenly diagnosed NPV in patients with an anatomically atretic PV may lead to a delay in the appropriate surgical management for singleventricle palliation. However, it is difficult to differentiate these 2 conditions, because both are similarly characterized by severe cardiomegaly, TR, no PV leaflet excursion, and absent RVFF. Echocardiographic evaluation ${ }^{7,8}$ and retrograde aortography ${ }^{9}$ have been suggested to provide a solution to this problem. In this study, we aimed to compare the clinical outcomes of these 2 subsets and to determine the postnatal echocardiographic parameters that delineate the PV morphology.

\section{MATERIALS AND METHODS \\ Patients}

Among 72 patients with Ebstein's anomaly born at or transferred to the Asan Medical Center between April 1996 and January 2013, 29 were identified as having no RVFF on echocardiography performed on the date of birth. The cohort was broken down into 2 groups: patients with an NPV and patients with a dysmorphic and nonfunctioning PV (ie, APV). The NPV group consisted of 16 patients (11 female), and the APV group included 13 patients ( 7 female). The APV group included 10 patients with anatomic pulmonary atresia and 3 patients with critical pulmonary stenosis. PV morphology in the NPV group was confirmed by detecting a normally functioning PV on follow-up echocardiography $(n=15)$ or absence of waist at the level of the PV on balloon pulmonary valvuloplasty $(n=1)$. PV morphology in the APV group was confirmed by direct vision of the PV dysmorphism on surgical intervention $(n=10)$, presence of waist at the level of PV on balloon pulmonary valvuloplasty $(n=2)$, and definite muscular pulmonary atresia on initial echocardiography $(\mathrm{n}=1)$. Preterm infants (gestational age $<37$ weeks) were $31 \%$ of the total patients ( $9 /$ 29 ), and birth weight was $2.7 \pm 0.6 \mathrm{~kg}$. Gestational age was $36.6 \pm 3.1$ weeks in the NPV group and $36.9 \pm 1.9$ weeks in the APV group $(P=.6)$, and birth weight was $2.6 \pm 0.6 \mathrm{~kg}$ in the NPV group and $2.7 \pm 0.5 \mathrm{~kg}$ in the APV group $(P=.2)$. This study was approved by the institutional review board (No. S2015-0576), and the need for informed consent was waived because of the retrospective nature of the study.

\section{Echocardiographic Assessment}

Retrospective review of echocardiographic images obtained on the date of birth and thereafter was conducted using TomTec software (Image Arena VA version 4.6; TomTec Imaging Systems, Unterschleissheim, Germany). Echocardiographic variables measured for the discrimination of the 2 groups were as follows: the area of the right atrium, atrialized RV, functional RV, and left ventricle (LV) on a parasternal 4-chamber view at the end-diastolic phase; the ratio of function RV area to LV area; Great Ormond Street Hospital (GOSH) index, ${ }^{10} \mathrm{RV}$ index (functional RV area/body surface area) and LV index (LV area/body surface area), actual diameter and $Z$ score of the pulmonary valve annulus (PVA) on a parasternal RV outflow view; the diameters of the pulmonary artery at the level of the branch pulmonary artery bifurcation on a parasternal short-axis view; echocardiographic pulmonary artery index ${ }^{7}$; presence or absence of PV regurgitation; grade and peak velocity of TR; and dp/dt of the tricuspid valve.

\section{Statistical Analysis}

Data are presented as frequencies, medians with ranges, or means with standard deviations. Comparison of patient characteristics between the groups was performed using the Fisher exact test for categoric variables and Mann-Whitney $U$ test for continuous variables. The changes in the cardiothoracic ratio were analyzed using the mixed linear regression model. Risk-unadjusted nonparametric estimates of survival of the overall cohort and each group were plotted as Kaplan-Meier estimates, and nonparametric comparison of survival between the 2 groups was performed using the log-rank test. To identify the variable(s) predicting an NPV, logistic regression analysis was performed including the following variables: presence of fetal distress, gestational period, birth weight, GOSH index, TR grade, TR velocity, and PVA ( $Z$ score). Analyses were conducted using the Statistical Package of the Social Sciences software program (version 18.0, SPSS Inc, Chicago, Ill).

\section{RESULTS}

Nine patients died during the first year after birth ( 2 in the NPV group and 7 in the APV group), and there has been no late death since then. Median follow-up period of the survivors was 63 months (30-234 months). Biventricular or $11 / 2$ ventricular physiology was eventually achieved in 14 patients $(14 / 16,88 \%)$ in the NPV group and 2 patients $(2 / 13$, $15.3 \%$ ) in the APV group. In 4 patients in the APV group, the extracardiac conduit Fontan operation was performed between 33 and 44 months of age (Figure 2). Postnatal survival is depicted in Figures 3 and 4. Survival at 12 months in the whole cohort, NPV group, and APV group was $68 \%, 87 \%$, and $46 \%$, respectively. During the postnatal follow-up of the patients in the NPV group, RVFF was observed at approximately 10 days (1-15 days) after birth in all but 1 patient who died of circular shunting on the first day after birth. After the development of RVFF, prostaglandin E-1 administration was discontinued to induce spontaneous closure of the ductus. However, surgical closure of the ductus was necessary in 3 neonates with 


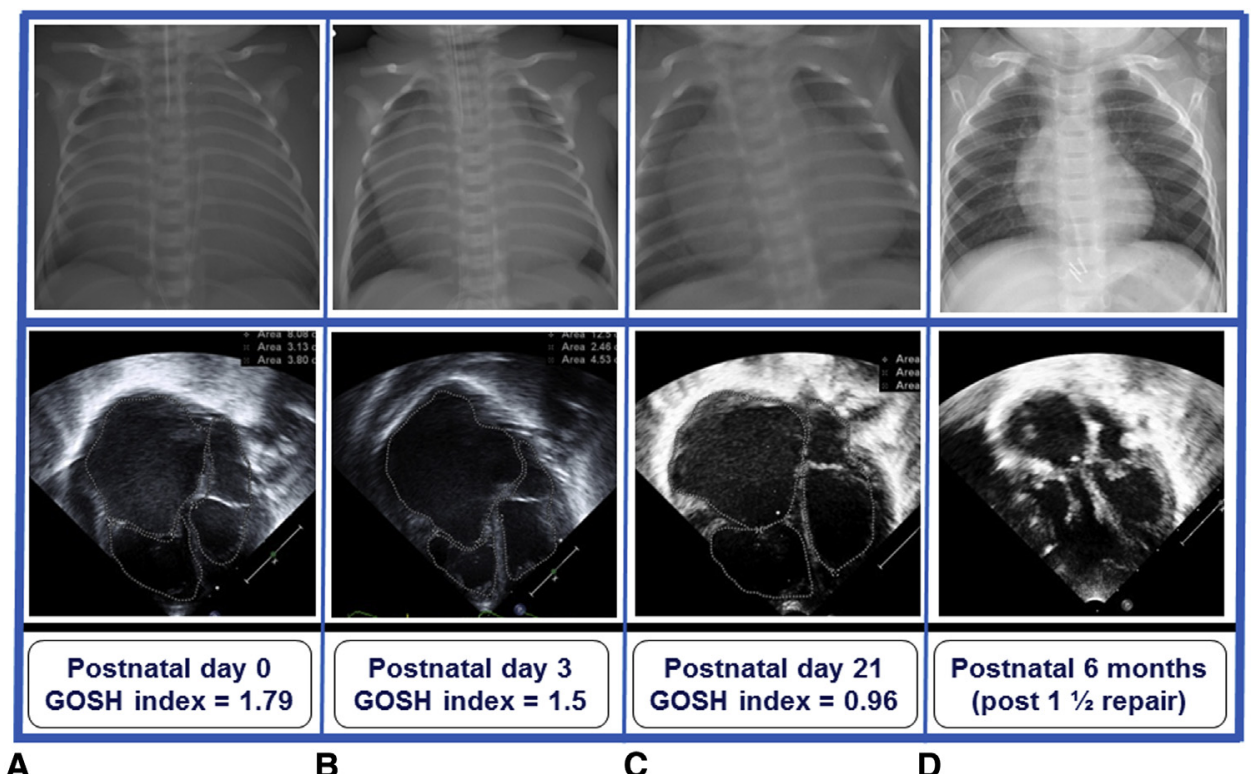

FIGURE 1. A, Clinical course of a neonate with severe Ebstein's anomaly and absent RVFF. RVFF developed in the patient on postnatal day 3 (B), and severe cardiomegaly gradually regressed with the increment of RVFF and closure of patent ductus arteriosus (C). She finally underwent tricuspid annuloplasty and bidirectional cavopulmonary shunt to constitute a $11 / 2$ ventricular repair at postnatal 6 months (D). GOSH, Great Ormond Street Hospital.

hemodynamic instability. The first patient died of desaturation and refractory arrhythmia after ductus ligation, and the second patient developed necrotizing enterocolitis before ductus ligation, which necessitated total colectomy and transverse loop jejunostomy. The clinical course of the third patient was uneventful after ductus ligation. There was a significant difference in cardiothoracic ratio $(0.79 \pm 0.05$ in the NPV group vs $0.85 \pm 0.07$ in the APV group, $P=.03$ ) on the initial chest $x$-ray. The NPV group showed a meaningful decrease in cardiothoracic ratio, whereas the APV group did not (NPV group: $P<.001$, APV group: $P=.1$; intergroup difference: $P=.02$ ) (Figure 5).

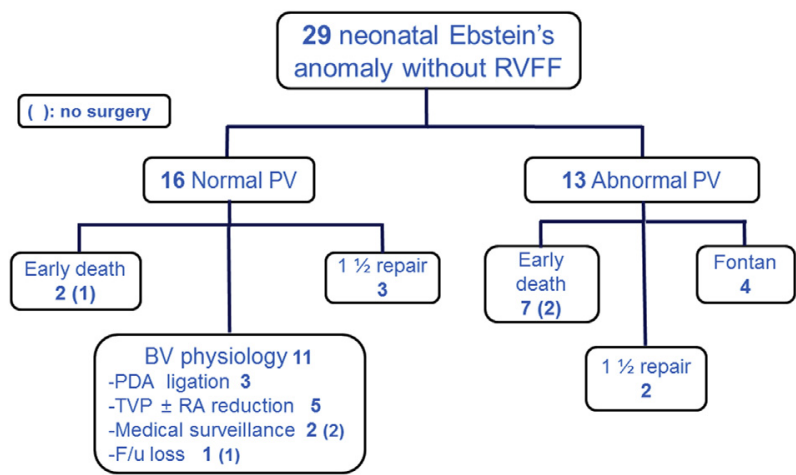

FIGURE 2. Clinical outcomes of neonate with Ebstein's anomaly according to $\mathrm{PV}$ morphology. $R V F F$, Right ventricular forward flow; $P V$, pulmonary valve; $11 / 2$, one-and-a-half ventricular; $B V$, biventricular; $P D A$, patent ductus arteriosus; TVP, tricuspid valvuloplasty; $R A$, right atrial; $F / u$, follow-up.
Table 1 lists the echocardiographic variables of the 2 groups. The NPV group had a significantly higher incidence of PR and larger PVA. There was no significant difference in Carpentier classification $(P=.13)$, GOSH index $(P=1.000)$, grade of TR $(P=.9)$, TR peak velocity $(P=.3)$, and $\mathrm{dP} / \mathrm{dt}$ of the tricuspid valve $(P=.9)$ between the 2 groups. On logistic regression analysis, only PVA size remained as a determinant indicating an NPV $(P=.03)$ (Table 2). Five patients in the APV group had a normally sized PVA, whereas no patients had a PVA $Z$ score of less than -1.15 in the NPV group. Mild to moderate pulmonary regurgitation (PR) was present in all patients $(16 / 16,100 \%)$

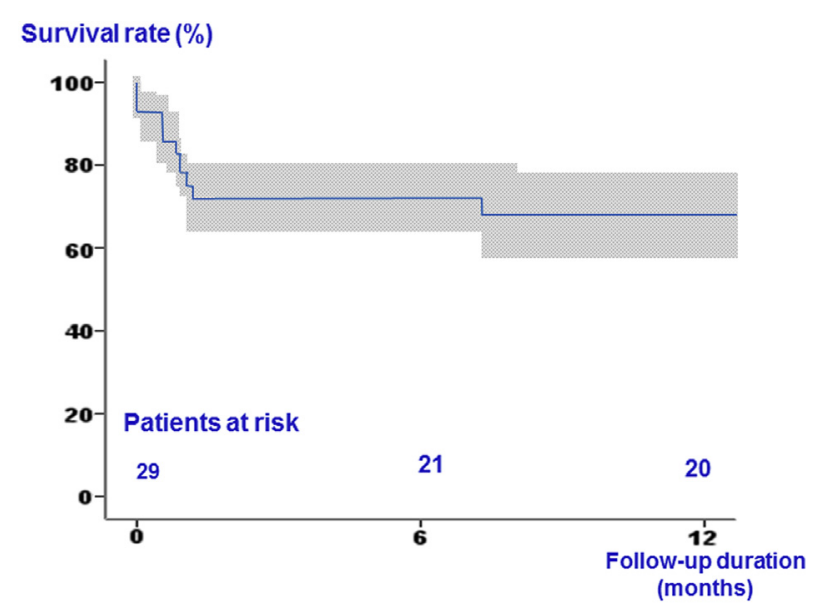

FIGURE 3. Postnatal survival of the entire cohort. 


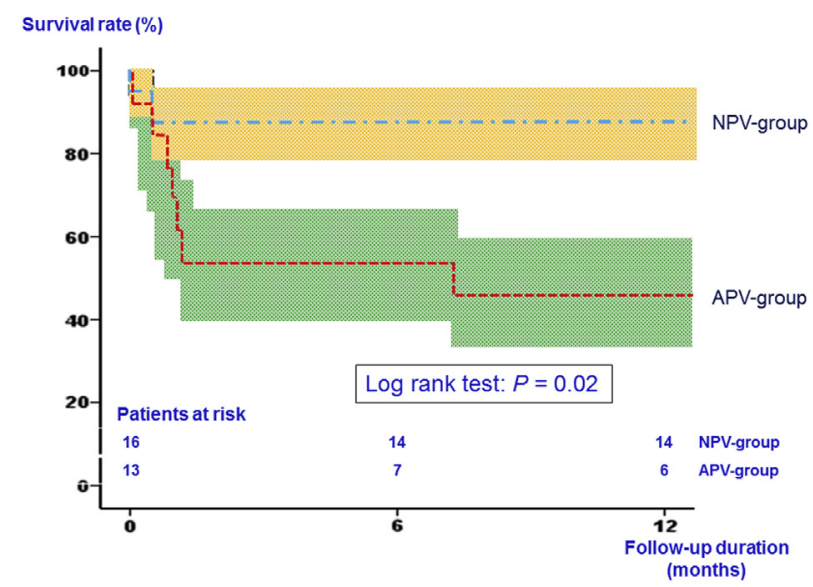

FIGURE 4. Postnatal survival of the 2 groups. $N P V$, Normal pulmonary valve; $A P V$, abnormal pulmonary valve.

in the NPV group, but 3 patients $(3 / 13,23 \%)$ in the APV group also had PR $(P=.01)$.

\section{DISCUSSION}

Absence of RVFF is frequently associated with severe Ebstein's anomaly even if it is also observed in a structurally normal heart. ${ }^{11}$ When it comes to describing the PV morphology in patients with Ebstein's anomaly and absent RVFF, the terms "anatomic" and "functional atresia" have been conventionally used. Given that most of the patients with functional atresia have PR, the term "atresia" (ie, disconnection between the proximal and distal chambers in the bloodstream) does not seem appropriate. Furthermore, the prognosis of this subset is mainly determined by the normal or abnormal morphology of the PV rather than simply by the presence or absence of the connection between the RV and the pulmonary artery. ${ }^{4,12,13}$ Even if biventricular repair or $11 / 2$ ventricle repair can be attempted in patients with pulmonary atresia or stenosis, the outcome is worse than that of the patients with an NPV.,12

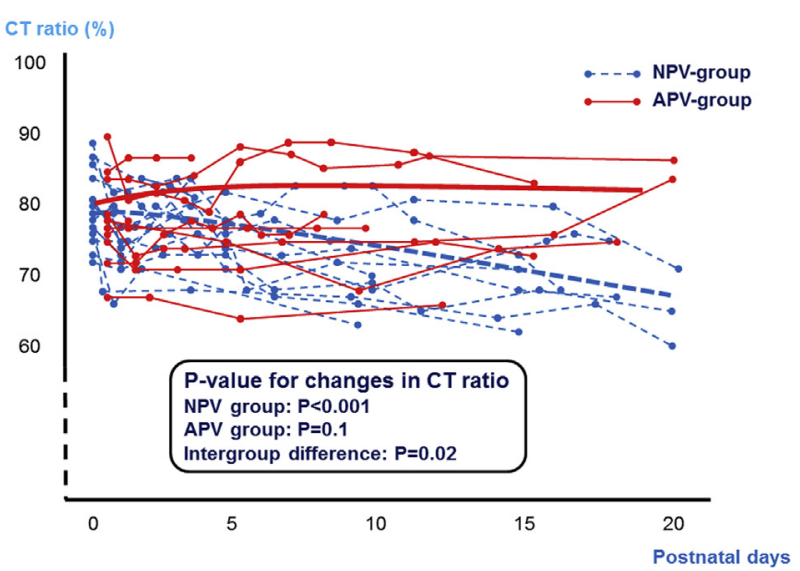

FIGURE 5. Changes in the cardiothoracic ratio on a chest $\mathrm{x}$-ray. $C T$, Cardiothoracic; $N P V$, normal pulmonary valve; $A P V$, abnormal pulmonary valve.
TABLE 1. Echocardiographic variables in both groups

\begin{tabular}{|c|c|c|c|}
\hline & $\begin{array}{c}\text { NPV group } \\
(\mathrm{n}=16)\end{array}$ & $\begin{array}{l}\text { APV group } \\
(\mathbf{n}=13)\end{array}$ & $P$ valu \\
\hline $\begin{array}{l}\text { Carpentier } \\
\quad \text { classification }\end{array}$ & & & .1 \\
\hline A & 6 & 3 & \\
\hline B & 4 & 10 & \\
\hline $\mathrm{C}$ & 1 & 5 & \\
\hline GOSH index & & & 1.0 \\
\hline 1 & 1 & 1 & \\
\hline 2 & 3 & 9 & \\
\hline 3 & 4 & 5 & \\
\hline 4 & & 3 & \\
\hline $\operatorname{RAA}\left(\mathrm{cm}^{2}\right)$ & $6.2(1.7-11.0)$ & $5.0(2.9-11.9)$ & .6 \\
\hline $\operatorname{aRVA}\left(\mathrm{cm}^{2}\right)$ & $1.5(0.3-5.7)$ & $1.4(0.5-4.4)$ & .3 \\
\hline $\mathrm{fRVA}\left(\mathrm{cm}^{2}\right)$ & $3.1(0.7-5.5)$ & $3.1(1.1-4.2)$ & .7 \\
\hline LAA $\left(\mathrm{cm}^{2}\right)$ & $1.9(1.2-4.0)$ & $1.9(1.2-3.6)$ & .7 \\
\hline $\operatorname{LVA}\left(\mathrm{cm}^{2}\right)$ & $3.3(2.1-6.2)$ & $3.0(2.3-8.7)$ & .4 \\
\hline fRVA/LVA & $0.8(0.20-1.9)$ & $1.1(0.1-1.6)$ & .7 \\
\hline $\begin{array}{l}\mathrm{RV} \text { index } \\
\quad\left(\mathrm{RVA} / \mathrm{BSA}, \mathrm{cm}^{2} / \mathrm{m}^{2}\right)\end{array}$ & $15.7(4.2-24.8)$ & $18.5(4.9-24.9)$ & .4 \\
\hline $\begin{array}{l}\text { LV index } \\
\quad\left(\mathrm{LVA} / \mathrm{BSA}, \mathrm{cm}^{2} / \mathrm{m}^{2}\right)\end{array}$ & $17.8(8.9-29.8)$ & $17.9(12.4-37.4)$ & .5 \\
\hline Severe TR (IV/IV) & $8 / 16(50 \%)$ & $7 / 13(54 \%)$ & .9 \\
\hline TR velocity $(\mathrm{m} / \mathrm{s})$ & $3.0 \pm 0.7$ & $3.2 \pm 0.9$ & .3 \\
\hline PV diameter (mm) & $8.2 \pm 1.4$ & $6.4 \pm 1.8$ & .002 \\
\hline PVA ( $Z$ score $)$ & $0.6(-1.3$ to 2.4$)$ & $-1.64(-3.3$ to 1.2$)$ & .001 \\
\hline $\operatorname{PAI}\left(\mathrm{mm}^{2} / \mathrm{m}^{2}\right)$ & $130(85-201)$ & $105(57-150)$ & .9 \\
\hline Presence of PR (n,\%) & $16 / 16(100 \%)$ & $3 / 13(23 \%)$ & .01 \\
\hline $\mathrm{RV} \mathrm{dp/dt} \mathrm{(mm} \mathrm{Hg/s)}$ & $433(220-1010)$ & $530(224-7111)$ & .9 \\
\hline $\begin{array}{l}\text { Development } \\
\text { of RVFF (d) }\end{array}$ & $11(1-15)$ & - & - \\
\hline
\end{tabular}

$N P V$, Normal pulmonary valve; $A P V$, abnormal pulmonary valve; $G O S H$, Grea Ormond Street Hospital; $R A A$, right atrial area; $a R V A$, atrialized right ventricular area; $f R V A$, functional right ventricular area; $L A A$, left atrial area; $L V A$, left ventricular area; $R V$, right ventricle; $R V A$, right ventricular area; $B S A$, body surface area; $L V$, left ventricle; $T R$, tricuspid regurgitation; $P V$, pulmonary valve; $P V A$, pulmonary valve annulus; $P A I$, pulmonary artery index; $P R$, pulmonary regurgitation; $R V F F$, right ventricular forward flow.

In patients with severe Ebstein's anomaly, RVFF may be absent as a result of an RV contractility-afterload mismatch ${ }^{14}$ or an anatomic obstruction in the PV. Discrimination between these 2 conditions is important in terms of the prediction of prognosis and selection of appropriate therapeutic strategies for each patient. ${ }^{15}$ However, it is difficult to assess the PV morphology in patients with absent RVFF because valve excursion, which is the key to an accurate diagnosis of valve morphology on echocardiography, is not observed. In patients with an NPV, ductal patency may or may not be beneficial. Ductus needs to be patent for survival before the development of RVFF. However, once RVFF commences, ductal patency may be harmful because it may hamper further increments in RVFF, and, more important, it may cause circular shunt ${ }^{1}$ and hemodynamic instability. In this study, there was a patient in the NPV group who died of devastating circular shunt on the day 
TABLE 2. Logistic regression analysis to identify predictors for normal pulmonary valve

\begin{tabular}{llllllll}
\hline & \multicolumn{3}{c}{ Univariate analysis } & & \multicolumn{3}{c}{ Multivariate analysis } \\
\cline { 2 - 4 } \cline { 7 - 8 } \multicolumn{1}{c}{ Variables } & OR & $\mathbf{9 5} \% \mathbf{C I}$ & $\boldsymbol{P}$ value & & OR & $\mathbf{9 5 \%}$ CI & $\boldsymbol{P}$ value \\
\hline Fetal distress & 1.4 & $0.2-11.7$ & .8 & & & \\
GP & 1.1 & $0.8-1.5$ & .5 & & & \\
Birth weight, $\mathrm{kg}$ & 2.9 & $0.6-13.0$ & .2 & & & \\
GOSH index & 0.8 & $0.2-4.2$ & .8 & & & \\
TR grade & 0.8 & $0.3-1.9$ & .6 & & & \\
TR velocity & 0.8 & $0.3-2.0$ & .6 & & & \\
PVA $(Z$ score $)$ & 2.7 & $1.3-5.8$ & .01 & 2.63 & $1.1-6.2$ & .03 \\
\hline
\end{tabular}

$O R$, Odds ratio; $C I$, confidence interval; $G P$, gestational period; $G O S H$, Great Ormond Street Hospital; $T R$, tricuspid regurgitation; $P V A$, pulmonary valve annulus.

of birth. Discontinuation of prostaglandin E-1 to limit the ductal blood flow might have alleviated the clinical deterioration in this case. Surgical closure of the ductus should be performed in a timely fashion if ductus remains patent after the discontinuation of prostaglandin E-1. Too early surgical attempts resulting in insufficient pulmonary blood flow may be as hazardous as belated intervention after the development of the complications caused by pulmonary overcirculation through the patent ductus. In our series, surgical closure of the ductus was necessary in 3 neonates. However, timely surgical closure of the ductus was performed in only 1 patient because 1 patient died of desaturation and refractory arrhythmia after ductus ligation (ie, too early intervention), and the other patient underwent surgical intervention after the development of necrotizing enterocolitis (ie, too late intervention).

This study suggests that the size of the PVA can be used to discriminate a normal and a dysmorphic PV in symptomatic neonates with Ebstein's anomaly and absent RVFF. In a previous study, ${ }^{7}$ echocardiographic parameters including the ratio of RV and LV end-diastolic dimensions, percent of normal predicted tricuspid valve ring diameter, peak TR velocity, and estimated RV pressure were measured to differentiate functional from anatomic pulmonary atresia. According to the analysis by Hiraumi and colleagues, ${ }^{7}$ all patients with functional atresia showed a ratio of RV and LV end-diastolic dimensions greater than 0.6 , percent of normal predicted tricuspid valve ring diameter greater than $100 \%$, peak TR velocity less than $4 \mathrm{~m} / \mathrm{s}$, and estimated $\mathrm{RV}$ pressure less than $50 \mathrm{~mm} \mathrm{Hg}$. However, these criteria are not applicable to patients with Ebstein's anomaly, as mentioned in their study, ${ }^{7}$ because the ventricular myocardium in patients with Ebstein's anomaly invariably has both structural and functional abnormalities. Even if PVA size was identified as the only predictor of a normally functioning PV, some patients with anatomic pulmonary atresia also had an NPV annulus size in this study. Fusion of the commissure at a late stage in fetal life may be due to this phenomenon, and this can be a caveat when using PVA size for the prediction of PV morphology.
Another important finding in our study was that the presence of PR does not necessarily signify an NPV. Previous reports emphasized the significance of $\mathrm{PR}$ in discriminating functional from anatomic pulmonary atresia. ${ }^{8,16}$ However, in our study, there were 3 patients with PR in the APV group. Even if the difference in the prevalence of $\mathrm{PR}$ in each group reached statistical significance (16/16 vs $3 / 13$, $P=.014)$, it is deemed rational not to regard PR as a crucial criterion of an NPV. Of the 3 patients with preoperative PR in the APV group, 1 died of low cardiac output after balloon pulmonary valvuloplasty and 2 eventually underwent the Fontan procedure.

\section{CONCLUSIONS}

The PVA diameter is a useful parameter indicating PV morphology in patients with severe Ebstein's anomaly. The presence of PR does not necessarily signify a functioning PV. There was a stark difference in mortality rates and final outcomes between the 2 groups. Therefore, timely and accurate identification of PV morphology may help improve the clinical outcomes of patients with Ebstein's anomaly and absent RVFF.

\section{Conflict of Interest Statement}

Authors have nothing to disclose with regard to commercial support.

\section{References}

1. Wald RM, Adatia I, Van Arsdell GS, Hornberger LK. Relation of limiting ductal patency to survival in neonatal Ebstein's anomaly. Am J Cardiol. 2005;96:851-6.

2. Yu JJ, Yun TJ, Won HS, Im YM, Lee BS, Kang SY, et al. Outcome of neonates with Ebstein's anomaly in the current era. Pediatr Cardiol. 2013;34:1590-8.

3. Yun TJ, Lee SH, Ko JK. Neonatal stenotic Ebstein's anomaly: a novel technique of right ventricular exclusion. J Thorac Cardiovasc Surg. 2006;131: 469-71.

4. Reemtsen BL, Fagan BT, Wells WJ, Starnes VA. Current surgical therapy for Ebstein anomaly in neonates. J Thorac Cardiovasc Surg. 2006;132: 1285-90.

5. Sano S, Fujii Y, Kasahara S, Kuroko Y, Tateishi A, Yoshizumi K, et al. Repair of Ebstein's anomaly in neonates and small infants: impact of right ventricular exclusion and its indications. Eur J Cardiothorac Surg. 2014;45:549-55.

6. Starnes VA, Pitlick PT, Bernstein D, Griffin ML, Choy M, Shumway NE. Ebstein's anomaly appearing in the neonate. A new surgical approach. J Thorac Cardiovasc Surg. 1991;101:1082-7.

7. Hiraumi Y, Watanabe K, Tomita H, Kurosaki K, Saito A, Tanizawa T, et al. Doppler echocardiographic differentiation of functional from anatomical pulmonary atresia: analysis using qualitative parameters. Circ J. 2002;66:665-7.

8. Smallhorn JF, Izukawa T, Benson L, Freedom RM. Noninvasive recognition of functional pulmonary atresia by echocardiography. Am J Cardiol. 1984;54: 925-6.

9. Freedon RM, Culham G, Moes F, Olley PM, Rowe RD. Differentiation of functional and structural pulmonary atresia: role of aortography. Am J Cardiol. 1978; 41:914-20

10. Celermajer DS, Bull C, Till JA, Cullen S, Vassilikos VP, Sullivan ID, et al. Ebstein's anomaly: presentation and outcome from fetus to adult. J Am Coll Cardiol. 1994;23:170-6.

11. Altun G, Babaoğlu K, Binnetoğlu K, Kavas N, Arısoy AE. Functional pulmonary atresia in newborn with normal intracardiac anatomy: successful treatment with inhaled nitric oxide and pulmonary vasodilators. Ann Pediatr Cardiol. 2013;6: 83-6. 
12. Boston US, Goldberg SP, Ward KE, Overholt ED, Spentzas T, Chin TK, et al. Complete repair of Ebstein anomaly in neonates and young infants: a 16-year follow-up. J Thorac Cardiovasc Surg. 2011;141:1163-9.

13. Yetman AT, Freedom RM, McCrindle BW. Outcome in cyanotic neonates with Ebstein's anomaly. Am J Cardiol. 1998;81:749-54.

14. Epstein M. Tricuspid atresia, stenosis, and regurgitation. In: Allen HD, Driscoll DJ, Shaddy RE, Feltes TF, eds. Moss and Adams' heart disease in infants, children, and adolescents: including the fetus and young adults. 7th ed. Philadelphia, PA: Lippincott Williams \& Wilkins; 2008: 817-34.
15. Knott-Craig CJ, Goldberg SP, Ballweg JA, Boston US. Surgical decision making in neonatal Ebstein's anomaly: an algorithmic approach based on 48 consecutive neonates. World J Pediatr Congenit Heart Surg. 2012;3:16-20.

16. Weinhaus L, Jureidini S, Nouri S, Connors RH. Functional pulmonary atresia: color flow recognition and treatment with extracorporeal membrane oxygenation. Am Heart J. 1990;119:980-2.

Key Words: Ebstein's anomaly, echocardiography, pulmonary valve

Readers who found these articles interesting may also like to read the following papers found in recent and future issues of our sister publications, Seminars in Thoracic and Cardiovascular Surgery and Operative Techniques in Thoracic and Cardiovascular Surgery!

\section{Congenital}

State of the Art: Interrupted Aortic Arch. Richard Jonas. Semin Thorac Cardiovasc Surg 2015; Summer; 27(2):177-188.

Original Submission: Should Tricuspid annuloplasty be performed with pulmonary valve replacement for pulmonary regurgitation in repaired tetralogy of fallot? Pranava Sinha. Semin Thorac Cardiovasc Surg 2015; Summer; 27(2): 159-165.

Editorial Commentary: PI Leads to RVE, Which Leads to TR, Which Leads to More RVE, Which Leads to More TR: A Vicious Cycle? Charles B. Huddleston. Semin Thorac Cardiovasc Surg 2015; Summer; 27(2): 166-167.

Original Submission: Unsatisfactory early and late outcomes after Fontan surgery delayed to adolescence and adulthood. Yves D'Udekem. Semin Thorac Cardiovasc Surg 2015; Summer; 27(2):168-174.

Editorial Commentary: The Fontan Operation: Is Timing Everything? Harold M. Burkhart. Semin Thorac Cardiovasc Surg 2015; Summer; 27(2): 175.

Discussions in Cardiothoracic Treatment and Care: Tetralogy of Fallot. Charles Fraser. Semin Thorac Cardiovasc Surg 2015; Summer; 27(2):189-204.

Original Submission: Preliminary experience in the use of an extracellular matrix (CorMatrix) as a tube graft: Word of caution. Narutoshi Hibino. Semin Thorac Cardiovasc Surg 2015; Autumn; 27(3):288-295.

Original Submission: Efficacy of artificial chordal reconstruction for idiopathic severe mittral regurgitation due to chordal rupture in infancy. Sadahiro Sai. Semin Thorac Cardiovasc Surg 2015; Autumn; 27(3):321-325.

Original Submission: The mid-term outcomes of bioprosthetic pulmonary valve replacement in children. Takeshi Shinkawa. Semin Thorac Cardiovasc Surg 2015; Autumn; 27(3):310-318.

Original Submission: Health-related quality of life in adult survivors after the Fontan operation. James Kirklin. Semin Thorac Cardiovasc Surg 2015; Autumn; 27(3):307-308.

Repair of Atrioventricular Septal Defects: The 2-Patch Sandwich Technique. Hagi Dekel. Oper Tech Thorac Cardiovasc Surg 2015; Spring; 20(1):63-74.

Classic Single-Patch Repair of Atrioventricular Septal Defects. Anees J. Razzouk. Oper Tech Thorac Cardiovasc Surg 2015; Spring; 20(1):75-86.

Microvascular Coronary Artery Repair and Grafting in Infancy and Early Childhood. Joseph Catapano. Oper Tech Thorac Cardiovasc Surg 2015; Summer; 20(2):148-161.

Repair of Anomalous Coronary Artery from the Pulmonary Artery by Aortic Implantation. Anthony Azakie. Oper Tech Thorac Cardiovasc Surg 2015; Summer; 20(2):135-147.

No ventricular septal defect patch atrioventricular septal defect repair. Carl Backer. Oper Tech Thorac Cardiovasc Surg 2015; Autumn; 20(3):279-292.

Potts shunt for children with severe pulmonary hypertension. Pirooz Eghtesady. Oper Tech Thorac Cardiovasc Surg 2015; Autumn; 20(3):293-305. 